\title{
Heterogeneity in pre-monsoon aerosol types over the Arabian Sea deduced from ship-borne measurements of spectral AODs
}

\author{
D. G. Kaskaoutis ${ }^{1}$, M. C. R. Kalapureddy ${ }^{2}$, K. Krishna Moorthy ${ }^{3}$, P. C. S. Devara ${ }^{2}$, P. T. Nastos ${ }^{4}$, P. G. Kosmopoulos ${ }^{4}$, \\ and H. D. Kambezidis ${ }^{1}$ \\ ${ }^{1}$ Atmospheric Research Team, Institute for Environmental Research and Sustainable Development, National Observatory of \\ Athens, Lofos Nymphon, P. O. Box 20048, 11810 Athens, Greece \\ ${ }^{2}$ Physical Meteorology and Aerology Div., Indian Institute of Tropical Meteorology, Pashan, Pune 411008, India \\ ${ }^{3}$ Space Physics Laboratory, Vikram Sarabhai Space Centre, Trivandrum 695022, India \\ ${ }^{4}$ Department of Geology and Geoenvironment, University of Athens, University campus 15784 Athens, Greece
}

Received: 27 February 2009 - Published in Atmos. Chem. Phys. Discuss.: 21 October 2009

Revised: 29 April 2010 - Accepted: 10 May 2010 - Published: 26 May 2010

\begin{abstract}
Ship-borne sunphotometer measurements obtained in the Arabian Sea (AS) in the pre-monsoon season (18 April-10 May 2006) during a cruise campaign (ICARB) have been used to retrieve the Aerosol Optical Depth (AOD; $\tau)$ and the Ångström wavelength exponent $(\alpha)$. The continents surrounding the AS produce natural and anthropogenic aerosols that have distinctive influences on $\alpha$ and its spectral distribution. The $\alpha$ values were estimated by means of the least-squares method over the spectral bands $340-1020 \mathrm{~nm}$ and $340-870 \mathrm{~nm}$. The spectral distribution of AOD in logarithmic co-ordinates could be fit using a 2 nd order polynomial with higher accuracy in the wavelength band 340$1020 \mathrm{~nm}$ than in the $340-870 \mathrm{~nm}$ band. A polynomial fit analytically parameterizes the observed wavelength dependencies of AOD with least errors in spectral variation of $\alpha$ and yields accurate estimates of the coefficients $\left(a_{1}\right.$ and $\left.a_{2}\right)$. The coarse-mode (positive curvature in the $\ln \tau_{\lambda}$ vs. $\ln \lambda$ ) aerosols are mainly depicted in the Northern part of the AS closely associated with the nearby arid areas while fine-mode aerosols are mainly observed over the far and coastal AS regions. In the study period the mean AOD at $500 \mathrm{~nm}$ is $0.25 \pm 0.11$ and the $\alpha_{340-1020}$ is $0.90 \pm 0.19$. The $\alpha_{340-870}$ exhibits similar values $(0.92 \pm 0.18)$, while significant differences revealed for the constant terms of the polynomial fit ( $a_{1}$ and $a_{2}$ ) proportionally to the wavelength band used for their determination. Observed day-to-day variability in the aerosol load and
\end{abstract}

Correspondence to:

M. C. R. Kalapureddy

(kalapureddy1@gmail.com) optical properties are direct consequence of the local winds and air-mass trajectories along with the position of the ship.

\section{Introduction}

The characterization of aerosol particles and the spectral dependence of their optical properties are very important as they strongly influence the radiative properties (singlescattering albedo, asymmetry factor, refractive index) in the atmosphere (El-Metwally et al., 2008; Moorthy et al., 2009). The Arabian Sea (AS) region has a unique weather pattern because of the Indian monsoon and the associated winds that reverse direction seasonally. It is a location where the pristine air masses from the Southern Indian Ocean (IO) and the polluted air from Asia meet during winter and spring season, providing a very interesting area for aerosol studies (e.g., Ramanathan et al., 2001; Kalapureddy et al., 2009). Moreover, the investigation of the aerosols over oceans is important from the standpoint of understanding their anthropogenic and natural impacts as well as in estimating their contribution to radiative forcing (e.g., Haywood et al., 1999; Satheesh et al., 2006a; Moorthy et al., 2009). However, the high spatiotemporal variability and limited measurements of the aerosol physical and optical properties over oceanic regions makes it difficult to understand their impact on weather and hence climate change (Smirnov et al., 2009). Due to these reasons the oceanic regions surrounding India have always been the subject of importance and investigating extensively through various experimental campaigns.

Published by Copernicus Publications on behalf of the European Geosciences Union. 
The aerosol load and spatial distribution in the AS region are highly variable due to airmass origin, local and regional meteorology, El Nino - La Nina patterns, and location of the ITCZ (e.g., Moorthy and Satheesh, 2000; Moorthy et al., 2001; Ramachandran and Jayaraman, 2002; Li and Ramanathan, 2002). Several limited field experiments and cruise campaigns (e.g., INDOEX, ARMEX, ICARB) found large heterogeneity in the aerosol field, optical properties and types over AS (e.g., Ramanathan et al., 2001; Moorthy et al., 2005; Kalapureddy et al., 2009). Underlying it, higher AODs and steeper gradients have been noticed over the northern part of the AS which are mainly attributed to the advection of mineral dust from west Asia causing a large effect on the radiative forcing in the region (e.g., Satheesh et al., 2006a; Moorthy et al., 2001). In contrast, larger sea-salt contribution to the AOD was found over the southern AS during the summer monsoon season which is directly associated with stronger sea-surface winds (Satheesh et al., 2006b).

The chemical species that contribute significantly to the AODs over the AS have been shown to be sulfate, sea salt and nitrate, potassium, organics, Black Carbon (BC), dust, fly ash and ammonium (Savoie et al., 1987; Krishnamurti et al., 1998; Nair et al., 2004; Kumar et al., 2008). However, there is a seasonality to these distributions and large reduction in $\mathrm{BC}$ mass fraction over the AS region found from winter to summer affects the seasonal radiative forcing (Babu et al., 2004). In addition, several earlier estimates of the anthropogenic contribution to mean AOD over the AS and northern Indian Ocean ranged from $65 \%$ to $>90 \%$ (Satheesh et al., 1999; Ramachandran, 2004b). The total aerosol-mass concentration decreased from $80 \mu \mathrm{g} \mathrm{m}^{-3}$ near the Indian coast to a few tenths of $\mu \mathrm{g} \mathrm{m}^{-3}$ over the most distant oceanic regions. The large increase in the small-particle concentration near the coast was also consistent with the corresponding large increase in the Ångström exponent from 0.2 over the Indian Ocean to 1.4 near the Indian coast (Krishnamurti et al., 1998).

In the following years we might expect aerosol concentrations in this region to increase in response to the rapid economic development that is taking place in this region, especially in the Indian subcontinent. Therefore, there is a need for continuous and systematic efforts to monitor aerosol concentrations and optical properties over this region since the knowledge of their effects on the marine environment and in our changing planet is a real challenge.

An Integrated Campaign for Aerosols, gases and Radiation Budget (ICARB) (Moorthy et al., 2008) was conducted in the pre-monsoon season of 2006 over the Bay of Bengal (BoB), IO and AS. In the present study, we use the ICARB campaign ocean segment data over AS during the pre-monsoon season (April-May) of 2006 focusing on the AOD spectral variation and Ångström exponent curvature, which can constitute the basis for aerosol type discrimination over the area. Although the AS has been extensively studied by several researchers, achievements of the ICARB are unique in the sense that i) it was performed during a different season (April-May) when the synoptic winds are in transition from a continental type air mass to a marine type, ii) none of the earlier cruises covered the western and northwestern parts of the AS (west of $\sim 65^{\circ} \mathrm{E}$ ), and iii) a latitudinally and longitudinally gridded dataset of aerosol optical properties was collected over a three-week period which has shown the large spatial heterogeneity over the AS in several aerosol parameters (including AOD and its wavelength dependence). All these important issues are addressed in the present work.

The results are examined against total and size-resolved aerosol-mass concentration measured simultaneously in the marine atmospheric boundary layer (MABL) and in the whole atmospheric column. In addition, we also discuss extensively the errors and uncertainties involved in the estimation of the curvature of the $\ln (\mathrm{AOD}) \mathrm{vs} . \ln (\lambda)$ line over oceanic regions, where the AOD is relatively low and special attention was paid to calibrate the AOD values opposite to previous works. The inclusion of two wavelength bands for characterizing the aerosol optical properties reveals the effects of the wavelength in the aerosol microphysical properties, which can be significant over oceanic regions with a very heterogeneous aerosol field. These investigations are the very first showing the spatial distribution of the AOD curvature over the AS region.

\section{Data collection}

The whole set of oceanic segment measurements during the ICARB was conducted onboard the Oceanographic Research Vessel Sagar Kanya. AS region was covered in the second leg (SK223B) of the campaign, which started from the port of Kochi (on the west coast of India, Fig. 1) on 18 April and ended after 24 days at Goa port $\left(15.4^{\circ} \mathrm{N}, 73.8^{\circ} \mathrm{E}\right)$ on 11 May. It reached its farthest west point $\left(14^{\circ} \mathrm{N}, 58^{\circ} \mathrm{E}\right)$ on 22 April and 3 May 2006. The track of the ship cruise was designed in such a way that the maximum possible marine regions in the AS were covered during the period of observations (see Fig. 1). The three AS regions shown in the figure are i) coastal AS, less than $220 \mathrm{~km}$ from the coast, ii) mid AS, between 220 and $550 \mathrm{~km}$ from the coast and, iii) far AS, more than $550 \mathrm{~km}$ from the coast (Kalapureddy et al., 2009). The points on the track show the daily position of the ship at 05:30 UTC with the dates being identified beside with suffix A for April and My for May. The intense field phase of ICARB in the AS region covered the longitudinal sector $58^{\circ} \mathrm{E}-76^{\circ} \mathrm{E}$ with a latitudinal coverage from $8^{\circ} \mathrm{N}$ to $22^{\circ} \mathrm{N}$.

High temporal resolution $(\sim 10 \mathrm{~min})$ observations of direct-beam solar radiation were made using two (sunphotometer and ozonometer) handheld Microtops-II (Solar Light Company, USA) photometers. One photometer provides the AOD at 5 channels (340, 440, 500, 675 and 870) while the other the AOD at $1020 \mathrm{~nm}$, the columnar water vapor and the total column ozone, using three UV and two 
IR bands, one of them is $1020 \mathrm{~nm}$. The AODs were derived from the instantaneous solar flux measurements using the instruments internal calibration. The instruments are calibrated at JPL and calibration constants are stored in the instruments to evaluate AODs for each time of observation based on Langley technique. We have not calibrated the sun-photometers just before the cruise, but inter-comparison results with other recently calibrated sun-photometers used onboard found to be well within the mean variation of the measured parameters. With this inter-comparison results, we did not find any drastic deviation in the calibration values after the cruise. The field-of-view (FOV) of the Microtops-II is $2.5^{\circ}$, while the FWHM of the filters is in the range 5 to $10 \mathrm{~nm}$. We have checked the error in the AOD estimation at all wavelengths individually and found that the absolute error was well below or equivalent to \pm 0.03 (Morys et al., 2001), with larger values in the region of UV. Against previous analyses (Kalapureddy and Devara, 2008; Kalapureddy et al., 2009), special care was taken now on reducing the error in the AOD, since positive bias $(+0.03)$ at $340 \mathrm{~nm}$ or negative bias $(-0.03)$ at $1020 \mathrm{~nm}$ can strongly affect the results (mainly the constant terms $a_{1}$ and $a_{2}$ of the polynomial fit, see Eq. 2). Cachorro et al. (2004) have pointed out that an inaccurate calibration can lead to a diurnal cycle of the AOD (mainly in the UV) and would result in significant AOD errors at the wavelengths where the calibrations were off. In the present work, we have applied this technique of correction to each wavelength for eliminating the diurnal artifact of the AOD in the UV. It was also found that application of the method by Cachorro et al. (2004) at VIS and IR wavelengths does not significantly affect the AOD values.

On the other hand, Shaw (1980) reported anomalous weak absorption at $1010 \mathrm{~nm}$, possibly from water vapor, since the extinction at this wavelength increases when column water vapor (precipitable water, PW) increases. During ICARB the PW was found to be $2.22 \pm 0.44 \mathrm{~cm}$, ranging from 1.0 to $5.0 \mathrm{~cm}$ (Kalapureddy et al., 2008). So, a correction has to be done at the $\mathrm{AOD}_{1020}$ due to water-vapor effect. This was done here for the first time in contrast to previous works (e.g., Kalapureddy et al., 2008, 2009) where water-vapor absorption effects at $1020 \mathrm{~nm}$ were assumed negligible. The water-vapor absorption at $1020 \mathrm{~nm}$ was calculated using the absorption coefficient of SMARTS2.9.2 model (Gueymard et al., 1995), and found to be $\sim 0.0015$. The results showed that the water-vapor absorption ranged from 0.007 to 0.035 contributing to $\sim 3-15 \%$ in $\mathrm{AOD}_{1020}$. Eck et al. (2001) found a water vapor optical depth of $\sim 0.009$ for a tropical atmosphere with $4.0 \mathrm{~cm}$ of PW at $1020 \mathrm{~nm}$, using water vapor line spectrographic parameters as given by Giver et al. (2000). Although the water-vapor contribution to $\mathrm{AOD}_{1020}$ is very low, its consideration affects retrieval of $a_{1}$ and $a_{2}$.

There is another possible uncertainty associated with the $1020 \mathrm{~nm}$ channel due to the temperature-sensitivity of silicon detector at this wavelength $\left(\sim 0.002 /{ }^{\circ} \mathrm{C}\right.$ ) (Holben et al., 1998). This remains a source of uncertainty at $\mathrm{AOD}_{1020}$ that

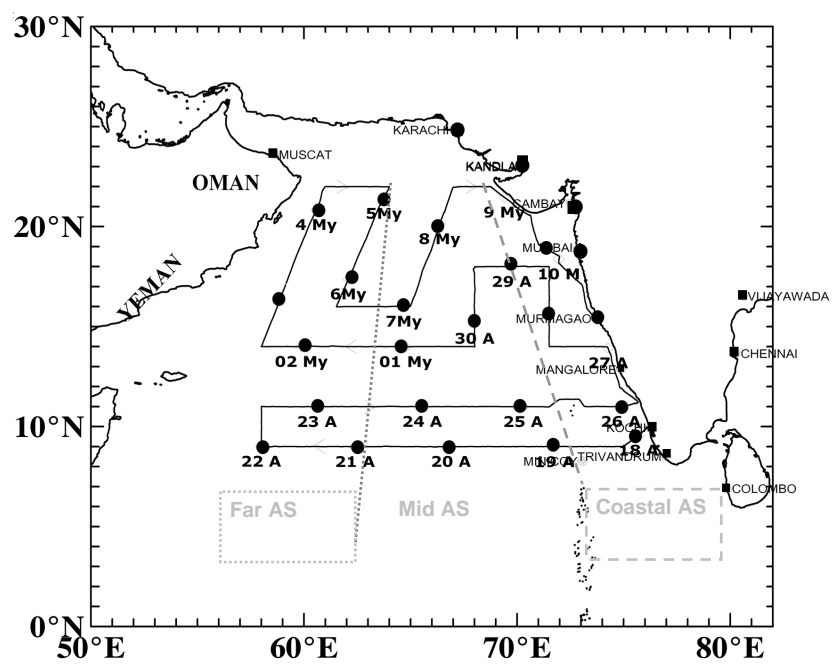

Fig. 1. The cruise legs (solid lines) of the Sagar Kanya 223B in the Arabian Sea in the period 18 April-10 May 2006 with indications of the daily position of the ship at 05:30 UTC denoted by the circles. The major ports and coastal urban centers on the mainland adjoining the cruise track are also identified. The date at each position also indicated ( $\mathrm{A}=$ April, $\mathrm{My}=$ May).

may not exist for the other wavelengths where the detector temperature sensitivity is insignificant. Although temperature sensitivity is likely a problem only during very clear conditions when the AOD is very small, the Microtops II algorithm does not take temperature sensitivity of the silicon photodiodes into account. Since Microtops-II does not have a built-in temperature sensor, temperature measured by the onboard meteorological system was used to further reduce the error of the $\mathrm{AOD}_{1020}$ estimation. Finally, the Microtops II was stored in a shaded area after each observation to minimize temperature variation and keep its internal temperature near constant.

Since the Microtops-II is a handheld instrument, there could be pointing errors and the magnitude of these errors would be higher on moving platforms. Since two different Microtops-II photometers (sunphotometer and ozonometer) were used in the study, the pointing accuracies could be also different. These pointing errors were reduced by mounting the two Microtops-II parallel to each other on a wooden plate, operating them simultaneously, and having the same observer throughout the cruise period make the sunphotometer measurements. Besides this, during each observation, three sets of measurements were collected in quick succession ( $\sim 1 \mathrm{~min})$ at each 10 -min time interval to minimize errors due to sun pointing on a moving platform. If the three measurements produced differences in the AODs above 5\%, those three data points were rejected for further analysis.

Great attention was given to choose which of the three measurements in each 10-min interval was used for further analysis. Of the three, the measurement that gave the best 
second-order polynomial fit to the $\ln \tau_{\lambda}$ vs. $\ln \lambda$ data points (Eck et al., 1999; Kaskaoutis et al., 2007a) was finally retained and the other two AODs were discarded. The fit was controlled by the highest $R^{2}$ associated with it, while cases with $R^{2}<0.92$ were omitted. In case the errors were close to each other, additional criteria were followed, such as the AOD values not to change significantly from the previous measurements or the spectral AOD variation to have as less spectral curvature as possible. Furthermore, data recorded around cloud passage or near the FOV of the instrument were not considered for analysis (Kalapureddy and Devara, 2008).

\section{Climatology of the area}

The climatology in the area is mainly dictated by the presence of monsoon, which divides the year into four periods. The mean winds are weak and predominantly from the north/northeastern direction during the winter monsoon season (December to March) where advection from the Indian continent is important. In the summer monsoon season (June to September) the mean winds are strong (10 to $15 \mathrm{~ms}^{-1}$ ) and blow mainly westerly/southwesterly favoring the advection from oceanic regions and western land areas. During March-June, it is hot and dry in the Africa, Arabian Peninsula and the Iranian desert regions, and the westerly winds carry significant amount of dust particles over Northern AS (Moorthy and Satheesh, 2000; Li and Ramanathan, 2002; Moorthy et al., 2005). A complete analysis of the wind pattern and rainfall over AS has been reported in Moorthy and Satheesh (2000). During the ICARB campaign, winds over the AS are mainly from the northwestern sector with an average speed of about 6 to $9 \mathrm{~ms}^{-1}$ (Kalapureddy and Devara, 2008). Precipitation was almost absent throughout the cruise period. A low level anticyclone centered over the central AS was the cause for the northwesterly winds; the associated winds were low. The mean synoptic wind pattern (derived from the NCEP-NCAR reanalysis data) at $850 \mathrm{hPa}$ over AS during ICARB showed strong westerlies over the northern part AS and weaker northerly/northeasterly over the southern part of AS (Nair et al., 2008).

\section{Theoretical background and methodology}

The spectral dependence of AOD $\left(\tau_{\lambda}\right)$ is frequently parameterized by the Angström exponent $\alpha$, which is computed from Ångström's (1961) empirical formula:

$\tau_{\lambda}=\beta \lambda^{-\alpha}$

where $\beta$ represents the aerosol load in the atmosphere and is equal to the AOD at the wavelength of $1 \mu \mathrm{m}$, while $\alpha$ is an indicator of the aerosol size or of the fraction of the finemode aerosols in the atmosphere (Schuster et al., 2006).
The validity of the Angström formula is predicated on the validity of the Junge power law (Junge, 1955) for the aerosolsize distribution, especially in range from 0.05 to $10 \mu \mathrm{m}$, where significant extinction takes place and the spectral variation of the refractive index does not impose significant variations on the Mie extinction factor. The Junge power law assumes a lognormal aerosol-size distribution that is far away from the bi-modal distribution of the aerosols in the atmosphere (e.g., Eck et al., 1999). Therefore, the Ångström formula in general is well fitted to the AOD values at the shorter or longer wavelengths. However, when the spectral range is extended, significant deviations from Eq. (1) may be found (Kaskaoutis and Kambezidis, 2006). This fact leads to the departure from linearity when the spectral AOD is plotted in logarithmic coordinates (Eck et al., 1999; Kaskaoutis et al., 2007a) and different $\alpha$ values can be obtained for different wavelength ranges (Reid et al., 1999; Kaskaoutis et al., 2007a). Even under these conditions when a curvature is observed in the $\ln \tau_{\lambda}$ vs. $\ln \lambda$ data points, the data still contain useful information about the aerosol type, size distribution and aerosol modification processes (e.g., coagulation, humidification) (King and Byrne, 1976; Eck et al., 1999; O' Neill et al., 2001; Gobbi et al., 2007; Basart et al., 2009). Therefore, a second order polynomial fit to the $\ln \tau_{\lambda}$ vs. $\ln \lambda$ data can give better accuracy than a linear fit:

$\ln \tau_{\lambda}=a_{2}(\ln \lambda)^{2}+a_{1} \ln \lambda+a_{o}$

where the coefficient $a_{2}$ accounts for the curvature often observed in sunphotometric measurements (Eck et al., 1999; Kaskaoutis et al., 2007a).

The ozone optical depth was subtracted in the derivation of the AOD, since its contribution to the total atmospheric optical depth can be significant under low turbidities. However, the absorption due to the trace-gases (mainly $\mathrm{NO}_{2}$ ) was assumed to be negligible as the AOD due to $\mathrm{NO}_{2}$ is generally $\sim 0.006$ (Tomasi et al., 1983; Kaskaoutis et al., 2007b). The Ångström parameters, $\alpha$ and $\beta$, were calculated via the leastsquares method in the spectral ranges 340-1020 nm and 340$870 \mathrm{~nm}$. According to the analysis performed by Kaskaoutis and Kambezidis (2008), this method is the least wavelength dependent for the calculation of the Angström parameters. The second-order polynomial fit (Eq. 2) was also applied to the AOD values at six wavelengths $(340,440,500,675,870$ and $1020 \mathrm{~nm}$ ), although any three of them were sufficient for this computation. As second-order polynomial fit was also applied to the five shorter wavelengths, excluding the 1020$\mathrm{nm}$ wavelength data, in order to investigate the differences in the retrieved parameters. Three typical examples of the spectral AOD variation over different parts of the AS are shown in Fig. 2. These measurements are taken (a) on 18 April when the ship was near to the western Indian coast, (b) on 29 April when the ship was crossing the northern part of AS, and (c) on 1 May in the far AS (see Fig. 1). Very different AOD values as well as wavelength dependence are revealed depending strongly on the aerosol type and fine-to-coarse ratio. On 


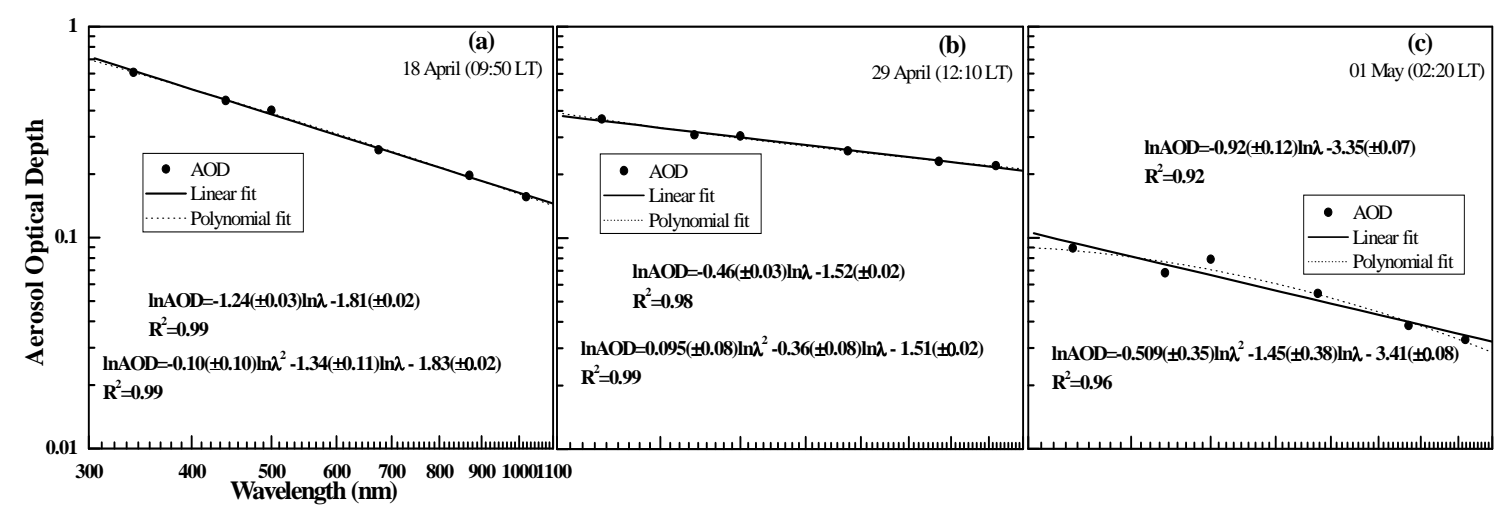

Fig. 2. Spectral variation of the AOD vs. wavelength in logarithmic scale for three distinct areas of AS, (a) near the Indian coast, (b) in the northern AS and, (c) in the far AS. The linear and the 2nd order polynomial fits for each case are shown.

18 April, the linear and 2nd order polynomial curves reveal excellent fit, with low uncertainties. Note the negative $a_{2}$ value and the high $\alpha$ value of the linear fit indicative of large presence of fine-mode aerosols near the coast. On 29 April, the above situation reverses, with the coarse-mode aerosols dominating (positive $a_{2}$ and low $\alpha$ value). The linear and polynomial fitting curves exhibit high accuracy in contrast to those of 1 May when significant uncertainties and errors in the retrieved parameters (e.g., $\alpha, a_{1}$ and $a_{2}$ ) occur in close association with the low AODs.

\section{Estimation of errors and uncertainties}

Before investigating the temporal and spatial variation of the aerosol features over the AS, a detailed analysis was carried out to estimate the errors and uncertainties of the 2nd order fit to the spectral AOD data. An account of the typical errors in the estimation of $a_{1}$ and $a_{2}$ (Eq. 2) is provided in this section. In general, the 2 nd order polynomial fit to the $\ln \tau_{\lambda}$ vs. $\ln \lambda$ data has been shown to provide good agreement with measured AODs, with standard errors of the fit on the same order as the uncertainty in the measurements. In contrast, the standard errors of the linear fit are significant with respect to the measured AODs (Eck et al., 2001; Kaskaoutis and Kambezidis, 2006). However, this is not always valid over oceanic regions with relatively low AODs (see Fig. 2). Figure 2 shows typical plots on the relation of AOD vs. wavelength with both linear and polynomial fits. Only Fig. 2c shows significant standard errors for both. Figure 3 shows the correlation of the typical errors in $a_{1}$ and $a_{2}$ computed in the two spectral bands (340-1020 nm and $340-870 \mathrm{~nm}$ ) with the AOD at $500 \mathrm{~nm}\left(\mathrm{AOD}_{500}\right)$. Large errors in the computed coefficients are seen for low $\mathrm{AOD}_{500}$ values $(<0.2)$ which themselves exhibit large variation. Nevertheless, as the atmospheric turbidity increases $\left(\mathrm{AOD}_{500}>0.3\right)$ the error in the estimates decreases dramatically. This feature is common in sunphotometric measurements and has been observed

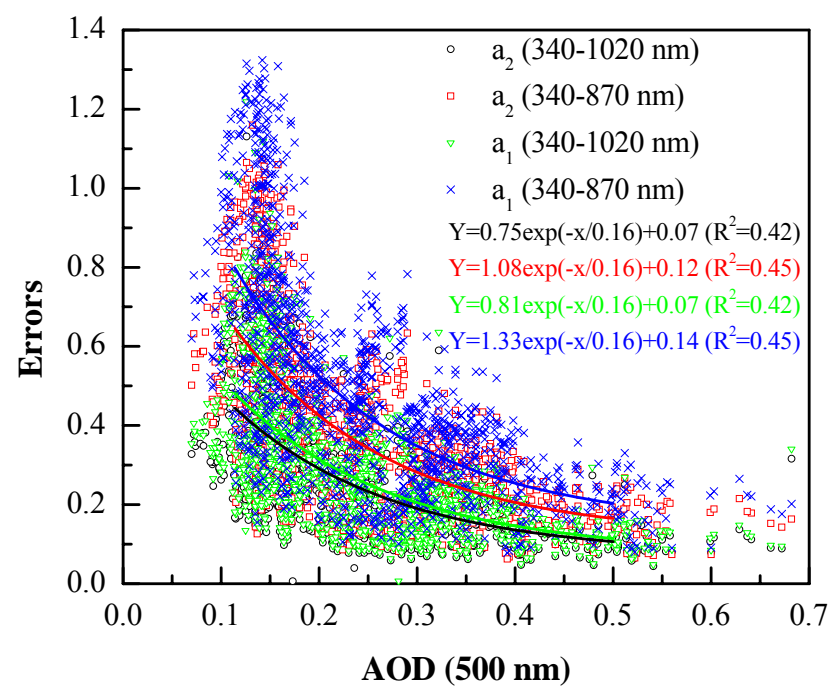

Fig. 3. Correlation of the errors in $a_{1}$ and $a_{2}$ obtained from the polynomial fit of the $\ln \tau_{\lambda}$ vs. $\ln \lambda$ in the two spectral bands with the $\mathrm{AOD}_{500}$ values.

in many studies (see Kaskaoutis et al., 2006 and references therein) and is attributed to the higher variability of the spectral AODs under these conditions.

The day-to-day variation of the uncertainties in $a_{1}$ and $a_{2}$ is presented in Fig. 4. Large uncertainties in $a_{1}$ and $a_{2}$ occurred in the period from 21 to 24 April and from 1 to 4 May, both periods having low AOD values (Fig. 3) as the ship was in the far AS (Fig. 1). On the other hand, low errors are present in the period from 25 to 27 April, the ship was near to Indian coast, and from 6 to 10 May (in the northern AS), both time periods with high AODs. When the spectral band 340-1020 nm was used for the polynomial fit, the errors were significantly lower in almost all cases, exhibiting mean values of erra $1=0.28 \pm 0.17$ and $\mathrm{erra}_{2}=0.25 \pm 0.16$ against those of erra $a_{1}=0.47 \pm 0.28$ and erra $_{2}=0.36 \pm 0.22$ for 

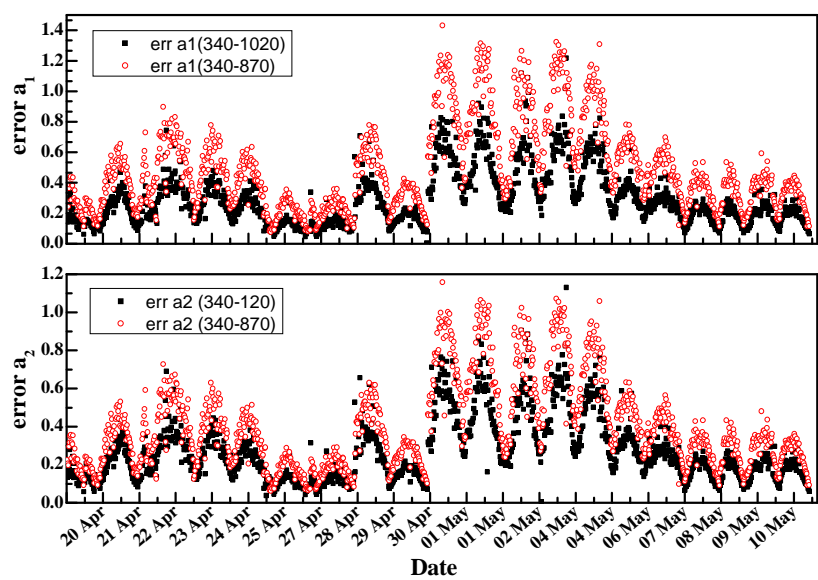

Fig. 4. Day-to-day variation of the errors in $a_{1}$ (top) and $a_{2}$ (bottom) in the spectral bands $340-1020 \mathrm{~nm}$ and $340-870 \mathrm{~nm}$.

the $340-870 \mathrm{~nm}$ band. The errors in $a_{1}$ and $a_{2}$ computations show the relative skill of the 2nd order polynomial fit (Eq. 2) in simulating the AOD spectral distribution and express the scatter of the AODs around the polynomial curve. Large errors in $a_{1}$ and $a_{2}$ lead to even larger uncertainty in the linear fit, which implies increased uncertainty in $\alpha$ (see Fig. 2). Note also that, according to Schuster et al. (2006) and Kaskaoutis et al. (2007a), $\alpha \approx a_{2}-a_{1}$. Therefore, the uncertainty in $a_{1}$ and $a_{2}$ drives the uncertainty in $\alpha$. It was found that the highest uncertainty in both $a_{1}$ and $a_{2}$ is found on days or cases where the curvature $\left(a_{2}\right)$ was both high and concave downward indicating the presence of fine-mode aerosols (see Fig. 2c). On the other hand, significant presence of coarsemode aerosols in the northern part of AS (29 April and 6-10 May) results in a bimodal aerosol size distribution where the linear and the second order polynomial fits present higher accuracies (see Fig. 2b), as also proved by Eck et al. (1999). As will be seen in the following, on the days of high errors (2124 April and 1-4 May), when the ship was cruising in the far AS, the $\alpha$ values were the highest. High curvature translates into higher scatter of the AOD values, further uncertainties in the linear fit and, therefore, larger error in the $\alpha$ retrievals (Kaskaoutis et al., 2006). The correlations between the errors in $a_{1}$ and $a_{2}$ with the Ångström exponent $\alpha$ for each of the two spectral bands are:

$$
\begin{aligned}
& \operatorname{erra}_{2}=0.504 \alpha+0.566, R^{2}=0.30(340-1020 \mathrm{~nm}) \\
& \operatorname{erra}_{1}=0.473 \alpha+0.568, R^{2}=0.29(340-1020 \mathrm{~nm}) \\
& \operatorname{erra}_{2}=0.319 \alpha+0.795, R^{2}=0.34(340-870 \mathrm{~nm}) \\
& \operatorname{erra}_{1}=0.259 \alpha+0.795, R^{2}=0.34(340-870 \mathrm{~nm})
\end{aligned}
$$

The above equations reveal a covariance between $\alpha$ and the uncertainty in the computed parameters $\left(a_{1}\right.$ and $\left.a_{2}\right)$, despite the large scatter. In general, the uncertainty increases with increasing $\alpha$ although their correlation is not as high as that of $\mathrm{AOD}_{500}$ (Fig. 3). Thus, there are several cases associated with large $\alpha$ and low errors, mainly when the ship was near to the coast; in these cases the AOD is high (see Fig. 2a). These results are in general agreement with those reported by previous researchers (Eck et al., 1999; Kaskaoutis et al., 2007a), which showed that the 2nd order polynomial fit presents larger uncertainties for large fine-mode aerosol fraction, while the fit seems to be more accurate for bimodal aerosol size distributions with a large coarse-mode fraction.

According to Schuster et al. (2006), $\alpha$ is equal to the difference $a_{2}-a_{1}$ to a first approximation. When the curvature is negligible $\left(a_{2} \approx 0\right)$, then $\alpha \approx-a_{1}$. The correlation between $\alpha$ and $a_{1}$ showed significant scatter for both spectral bands (340-1020 nm and 340-870 nm). However, the correlation was somewhat better using the first spectral band $\left(R^{2}=0.63\right.$, against 0.61 for $380-870 \mathrm{~nm}$ ). It is worth noting here that special care was taken in the present work on validating the AOD data (e.g., application of the Cachorro et al. (2004) method, consideration of PW and temperature effects), and this improves the $\alpha$ vs. $a_{1}(340-1020 \mathrm{~nm})$ relationship compared to that presented in Kalapureddy et al. (2009), where the $R^{2}$ was 0.37 . Considering the scatter of $\alpha$ vs. $a_{1}$ the role of the curvature in the spectral AOD becomes significant. Consequently, the inclusion of the spectral curvature in the analysis enhances the knowledge about the volume fraction and effective radius of the fine-mode aerosols at intermediate values of $\alpha$ (Schuster et al., 2006). The correlation between the $\alpha$ and $a_{2}-a_{1}$ is shown in Fig. 5 for the spectral bands $340-1020 \mathrm{~nm}$ and $340-870 \mathrm{~nm}$. The two are highly correlated, as indicated by the $R^{2}$ values of $0.96(340-870 \mathrm{~nm})$ and $0.99(340-1020 \mathrm{~nm})$. Data points lying on the $x=y$ line, or closely around it, indicate the validity of the relation $\alpha=a_{2}-a_{1}$. According to our analysis, the scattered points (340-870 nm case) correspond to cases where the secondorder polynomial fit does not provide high accuracy. These findings are in agreement with those by Schuster et al. (2006) who concluded that the relation $\alpha=a_{2}-a_{1}$ can be considered valid for bimodal size distributions with equivalent contributions from fine- and coarse-mode particles. A systematic overestimation of the $a_{2}-a_{1}$ against $\alpha$ is observed for high $\alpha$ values (>1.0) (upper panel), while is absent for $\alpha<0.7$. Schuster et al. (2006) reported that the condition $a_{2}-a_{1} \geq 2$ corresponds to size distributions dominated by fine-mode aerosols and the $a_{2}-a_{1} \leq 1$ to size distributions dominated by coarse-mode particles, whereas intermediate values of $a_{2}-a_{1}$ to a wide range of fine-mode fractions. Values greater than 2 are absent in our study, while a significant number of values $<1.0$ is observed in both graphs. From the above analysis it is established that the use of the 340-1020-nm spectral band for the calculation of $\alpha, a_{1}$ and $a_{2}$ values leads to the most precise results with the lowest curvature. This fact also indicates the great effort and attention spent on the accuracy of the $\mathrm{AOD}_{1020}$. 

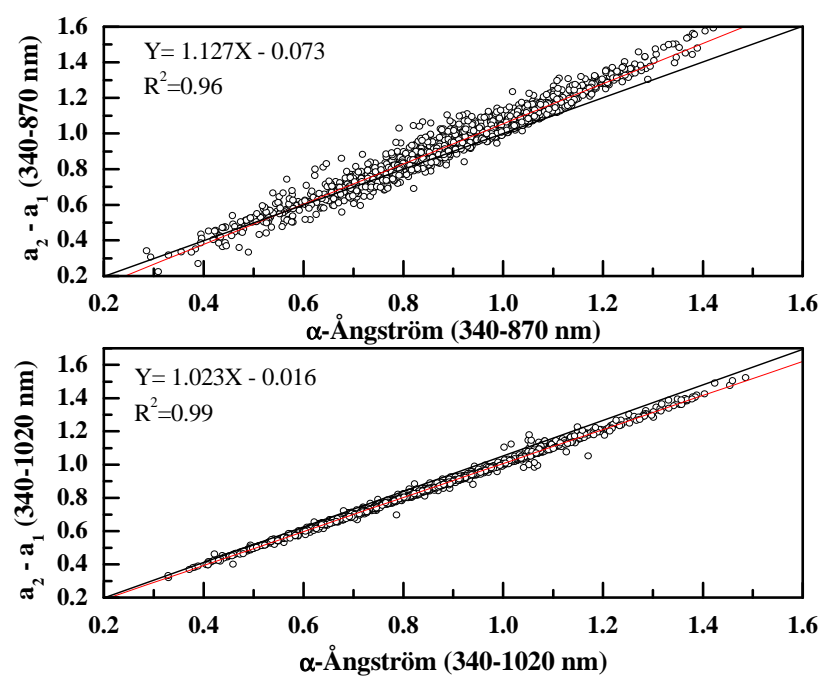

Fig. 5. Correlation between the differences $a_{2}-a_{1}$ and the $\alpha$ values in two different spectral bands. The black lines represent the $y-x$ condition and the red line the linear equation given in the graph.

\section{Results}

\subsection{Daily variation of the aerosol properties}

Figure 6 presents the day-to-day variation of spectral AOD and $\alpha$, at high temporal $(\sim 10 \mathrm{~min})$ resolution for the AS region during ICARB. These observations compared well with the daily mean $\mathrm{AOD}_{500}$ temporal variation of other ICARB data (Kedia and Ramachandran, 2008a) as well as with MODIS (Terra and Aqua) observations (Kalapureddy and Devara, 2008). The AOD at $340 \mathrm{~nm}(0.31 \pm 0.14)$ is significantly higher than at longer wavelengths, $0.15 \pm 0.07$ at $870 \mathrm{~nm}$ and $0.13 \pm 0.07$ at $1020 \mathrm{~nm}$ (Fig. 6 upper panel). The $\mathrm{AOD}_{500}$ varies significantly from 0.07 to 0.71 thus implying large variability in aerosol load over the entire AS during ICARB. The mean $\mathrm{AOD}_{500}$ was found to be $0.25 \pm 0.11$, which is significantly higher than that observed over open oceanic regions in Pacific and Atlantic oceans (Smirnov et al., 2002). However, the $\mathrm{AOD}_{500}$ over AS is much lower than that observed over $\mathrm{BoB}(0.36 \pm 0.12)$ during pre-monsoon (March-April 2006) ICARB (Kalapureddy and Devara, 2008), or from previous studies (e.g., Ramachandran, 2004a). During periods when the ship was nearer to the Indian coast, (e.g., 18-19, 25-27 April) the spectral AOD variation is larger due to the proximity to the urbanized costal harbors. It is known that aerosols of smaller size contribute more to the AOD at shorter wavelengths (e.g., Schuster et al., 2006) and the condensation growth and the coagulation mechanism of sub-micron aerosols are more efficient in producing larger (accumulation- and/or coarse-mode) aerosols than primary production (Fitzgerald, 1991; Moorthy et al., 1999). These processes are more efficient over coastal regions due to larger amount of hygroscopic components in the

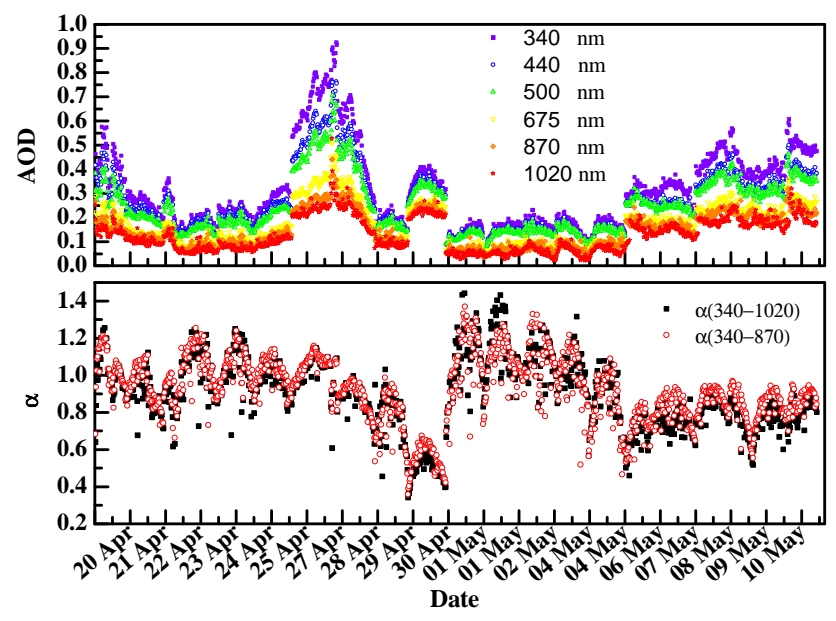

Fig. 6. Temporal variation of the spectral AOD (top) and Ångström exponent $\alpha$ in two different spectral bands, 340-1020 nm and 340$870 \mathrm{~nm}$ (bottom) in the AS during the ICARB campaign.

coastal aerosol composition. The effluents from the anthropogenic activities can contribute to fine- and accumulationmode aerosols through secondary production mechanisms (condensation, coagulation, and gas-to-particle conversion) in the warm and humid tropical environment (Moorthy et al., 2005; Babu et al., 2008). As a direct consequence of the anthropogenic emissions in the industrialized ports of the Indian west coast, the AODs present the highest values in the period from 25 to 27 April. Another significant aspect is the low AODs from 1 to 4 May, when the ship was far away from land. On the other hand, on 29 April and on the last days of the cruise the AODs at longer wavelengths are comparable in magnitude with those of 25-27 April. However, the AODs at shorter wavelengths are much lower, thus indicating aerosol presence of different origin and composition than the previous ones.

The day-to-day variation of the $\alpha$ values computed in the spectral bands $340-1020 \mathrm{~nm}$ and $340-870 \mathrm{~nm}$ is shown in Fig. 6 (lower panel). The two $\alpha$ values exhibit similar day-to-day variability and their mean values and standard deviations are $0.90 \pm 0.19$ for $340-1020$ and $0.92 \pm 0.18$ for $340-870$; their intercorrelation is statistically significant $\left(95 \%\right.$ confidence level) with $R^{2}=0.85$. These values agree with those of $0.86 \pm 0.20$ over AS and are significantly lower than that $(1.21 \pm 0.11)$ over BoB reported by Kalapureddy and Devara (2008) during ICARB For winter season, the average value of $\alpha$ for the period 1996-2000 was reported to be $1.50 \pm 0.05$ over AS, while $\beta$ was 0.10 (Ramachandran, 2004a), which is significantly higher than the values observed during our experiment. This difference might be attributed to both seasonal differences between the observations Ramachandru (2004a) and the ICARB measurements and differences in the spatial domain and sampling resolution. However, the mean $\alpha$ value measured by 
Ramachandru (2004a) in April for the period 1996-2000 was much lower, $1.27 \pm 0.07$. The $\alpha$ values in both spectral bands are larger than those found over open oceanic areas in Pacific (Lanai [0.76], Nauru [0.43] and Tahiti [0.74]) and Atlantic (Bermuda [0.93] and Ascension [0.62]) oceans (Smirnov et al., 2002). This indicates the higher influence of the continental anthropogenic aerosols of the Indian subcontinent that dominate the aerosol load over AS. Satheesh et al. (2006a) also found lower $\alpha$ values determined in the spectral band $380-1025 \mathrm{~nm}$ compared to those in $380-870 \mathrm{~nm}$. This means that as the wavelength region used for $\alpha$ determination shifts towards shorter wavelengths higher $\alpha$ values are observed, a fact that implies a convex-type curve in the $\ln \tau_{\lambda}$ vs. $\ln \lambda$ relationship, characteristic of aerosols with significant fraction of coarse-mode particles (Eck et al., 1999; Schuster et al., 2006; Kaskaoutis et al., 2007a). This is more pronounced on 29 April and from 6 to 10 May, where the $\alpha$ values are lower, indicative of the presence of coarse-mode aerosols. In contrast, from 1 to 4 May when $\alpha$ was larger, the $\alpha_{340-1020}$ seems to be larger than that at $340-870 \mathrm{~nm}$, implying a concave-type curve (Eck et al., 1999; Schuster et al., 2006; Kaskaoutis et al., 2007a). As previously noted, on the first days of the cruise when the ship was near the coast, the $\alpha$ values were high (above 1.0). The same feature was repeated between 1 to 4 May when the ship was in the far AS. It is rather unexpected to observe such high $\alpha$ values over an oceanic environment, but it was found that on those days the winds were rather low (below $5 \mathrm{~m} \mathrm{~s}^{-1}$ ) not favoring the production of marine aerosols. Therefore, with the absence of intense sea-surface winds and the absence of air masses originating from the arid landscapes surrounding AS from north and west, the aerosol loading over the area is mainly dominated by small anthropogenic components, thus explaining the relative high $\alpha$ values. In close agreement, chemical analysis of the aerosols over AS (George and Nair, 2008; Reddy et al., 2008) showed that the non-sea-salt component dominated even in far AS, indicating large fraction of the total aerosol mass was anthropogenic aerosols. In contrast, on 29 April and in the period 6-10 May, the $\alpha$ values were low indicating a significant fraction of coarse-mode particles in the total particulate mass. On these days, the research vessel was in the northern part of the AS and the aerosol populations were influenced by the nearby arid continental areas. The temporal and spatial variability of aerosol mass, chemical composition, and size distribution over AS could be due to both heterogeneity in the aerosol emissions from the Indian subcontinent and the variability in wind speed and relative humidity (George and Nair, 2008; Nair et al., 2008). As an example, surface winds during the monsoon season may produce abundant sea-spray over the adjoining seas, and the optical properties of marine aerosols so produced will be dominated by the large particles.

The coefficients $a_{1}$ and $a_{2}$ obtained by the polynomial fit (Eq. 2) in the AOD values using the spectral bands 340$1020 \mathrm{~nm}$ and $340-870 \mathrm{~nm}$ are shown in Fig. 7 (upper and

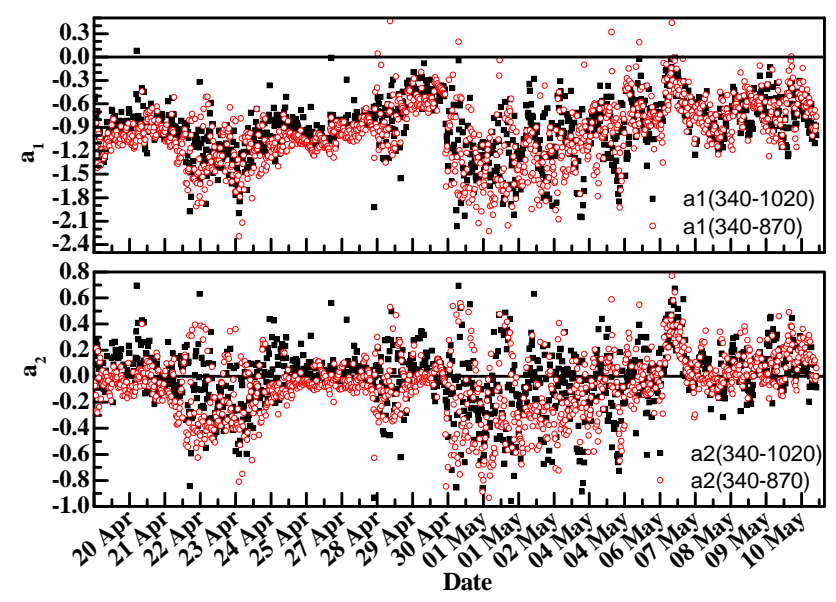

Fig. 7. Same as in Fig. 6, but for the coefficients $a_{1}$ (top) and $a_{2}$ (bottom) calculated in the 340-1020-nm and 340-870-nm spectral bands.

lower panel, respectively). Significant daily variability was observed in both $a_{1}$ and $a_{2}$. Large differences can also be observed even in a narrow (10-20 min) time interval, since the $a_{1}$ and $a_{2}$ values are very sensitive to any change in the AOD value at any wavelength. Due to further calibration of the AODs in the present work, $a_{1}$ and $a_{2}$ are somewhat different from the results of Kalapureddy et al. (2009). In both figures the $a_{2}$ values are negative in the majority of the cases $(51.5 \%$ for $340-1020 \mathrm{~nm}$ and $64.7 \%$ for $340-870 \mathrm{~nm}$ ) indicating a concave type curve in the $\ln \tau_{\lambda}$ vs. $\ln \lambda$ relation. This type of curve implies the presence of significant amount of fine-mode aerosols (Eck et al., 1999). Similar negative curvatures were also found over the tropical coastal Indian station, Visakhapatnam, during the summer monsoon period (Madhavan et al., 2008).

Presence of large negative $a_{2}$ values is observed on certain days (21 to 24 April and 1 to 4 May), when the research vessel was in the far AS region. Furthermore, the figure shows the presence of $a_{2}$ values close to zero on days when the ship was close to the western Indian coast (18-19 and 25-27 April), thus indicating a bimodal aerosol size distribution with a large contribution from coarse particles. The figure also shows positive $a_{2}$ values on 29 April and on the last days of the cruise, suggesting the presence of a significant fraction of coarse-mode aerosols advected from the dry desert regions. Previous studies using measurements (Eck et al., 1999; Kaskaoutis et al., 2007a; Basart et al., 2009) or theoretical approaches (Schuster et al., 2006) have shown that the curvature is larger (more negative $a_{2}$ values) in cases with significant fraction of fine-mode aerosols, with the curvature becoming negligible (close to zero or even positive $a_{2}$ values) in atmospheres dominated by bimodal aerosol size distributions or coarse-mode particles. These results agree with these previous observations and model output from the AS region. 
The $a_{1}$ varies widely from -2.16 to $0.08(340-1020 \mathrm{~nm})$ and from -2.29 to $0.46(340-870 \mathrm{~nm})$. The respective $a_{2}$ values range from -1.08 to 0.69 and from -0.93 to 0.76 . In general, the mean $a_{2}$ value $(-0.02 \pm 0.22)$ is lower (in absolute value) in the spectral range $340-1020 \mathrm{~nm}$ thus implying less curvature, on average, than that computed without the $\mathrm{AOD}_{1020}$ value $(-0.07 \pm 0.24)$. Assuming the curvature for $-0.1<a_{2}<0.1$ was negligible, it was found that the $\sim 46 \%$ of the cases lie within this limit when the 340 $1020 \mathrm{~nm}$ band was used. However the fraction of usable data is lower $(\sim 42 \%)$ for the band $340-870 \mathrm{~nm}$. These cases were mostly observed in the period 25-29 April and on the last days of the cruise when bimodal aerosol size distributions with intermediate values of $\alpha$ dominated. In these cases (587 for $340-1020 \mathrm{~nm}$ ) the errors in $a_{1}$ and $a_{2}$ computations are much lower ( 0.21 and 0.18 respectively) than those presented in Fig. 4. Furthermore, the $\alpha_{340-1020}$ value is 0.84 , which is nearly equal to the absolute value of $a_{1}=-0.85$. For the data using the $340-870 \mathrm{~nm}$ band, the uncertainties in $a_{1}$ and $a_{2}$ derived from the fits assuming negligible curvature (530 cases) are 0.34 and 0.27 , respectively. The mean $\alpha_{340-870}$ value is 0.83 , which agrees with the absolute $a_{1}=-0.86$. Regarding $a_{1}$, almost all of its values are negative, as expected, since $a_{1}=-\alpha$ on cases without curvature. However, some non-physical positive $a_{1}$ values were observed. The number of positive $a_{1}$ values is larger when they were computed in the 340-870-nm band (7 cases) against only 1 in the band of $340-1020 \mathrm{~nm}$. However, a significant fraction of positive $a_{1}$ values was observed in the clean marine environment of Nauru (Kaskaoutis et al., 2007a). From a detailed analysis it was established that these (positive) values are obtained in cases that $\mathrm{AOD}_{1020}>\mathrm{AOD}_{870}$ or when the AODs at the shorter wavelengths are much higher compared to those at the longer ones. It should be noted here that the additional calibration of the AODs (application of the Cachorro et al. (2004) method, consideration of the PW and temperature sensitivity effects) resulted in the presence of lower number of positive $a_{1}$ compared to the previous work (Kalapureddy et al., 2009). The positive $a_{1}$ values in the band of 340$870 \mathrm{~nm}$ are mainly attributed to the larger $\mathrm{AOD}_{870}$ values instead of the $\mathrm{AOD}_{675}$ values, a rather common characteristic in clean marine environments (Kaskaoutis et al., 2007a). However, these cases are very few over AS, a fact that differentiates this environment of background clean marine one. Also, the nearly absence of "unreal" positive $a_{1}$ values shows the accuracy of the AOD retrievals over a moving platform in an oceanic area.

During the pre-monsoon season, the dry Indian landscapes along with the anthropogenic activity would inject of significant amount of particulate matter in the atmosphere and transport them over AS. The air mass back trajectories for all the cruise days in the central part of AS indicate absence of any significant long-range transport from the adjoining continents, as the air masses seem to come from oceanic origin mainly for the 500-m level (George and Nair, 2008; Reddy et al., 2008). Further, It has been seen that sulfates and other continental aerosols are transported thousands of kilometers over AS and IO during the northeast monsoon season (Ramachandran and Jayaraman, 2002). These aerosols are responsible for the enhancement of $\alpha$ values in the central AS, since it was found (not presented) that the air-mass trajectories at $1500 \mathrm{~m}$ come from continental India when the ship was cruising the central part of AS. Meteorological studies showed that high aerosol concentrations could be linked to transport from the Indian subcontinent and also from sources in the Middle East and Arabian Peninsula (Moorthy et al., 2005). Although heavier aerosols may reside (via dry deposition) there still remains a strong possibility for fine dust aerosols from Arabia and other arid regions, whose size belongs to the accumulation size regime (Hess et al., 1998), to be transported over AS. Furthermore, mineral dust was found to be a substantial component in most of the aerosol samples collected in AS (Savoie et al., 1987; Nair et al., 2004; Kumar et al., 2008). Analyzing spectral AODs from a network of observatories over Indian mainland during ICARB, Beegum et al. (2008) showed the significant role of transported dust in enhancing AOD and decreasing $\alpha$ over the Indian subcontinent during April and over the northern part of India and the Indo-Gangetic Plains in May.

\subsection{Spatial distribution of the aerosol properties}

In this section the spatial distribution of aerosol features over the AS are presented. Similar AOD and $\alpha$ maps have already been published by Kalapureddy and Devara (2008) for the whole ICARB campaign, including BoB, IO and AS. In this work these graphs are presented over the AS in more detail for to survey the basic aerosol features that can aid in interpreting the results of the present work, while the spatial distributions of $a_{1}$ and $a_{2}$ are presented for the first time. It should be noted here that because the segment of the ICARB in the AS lasted about one month, it is certain that the aerosol parameters underwent changes due to changes in the synoptic situation. As such, some of the spatial features could be partly caused by these temporal changes. Figure 8 shows the spatial distribution of $\mathrm{AOD}_{500}$ and $\alpha_{340-1020}$ over AS region during the ICARB. There is a strong southwest-to-northeast gradient in the $\mathrm{AOD}_{500}$ values since the aerosol load over the northern part of AS is larger than that of the southern. However, the lowest $\mathrm{AOD}_{500}$ values are observed in the central part of AS (around $13-14^{\circ} \mathrm{N}$ ). When the research vessel was cruising in the north AS region, the advection of dust by the northwesterly winds cause an enhancement in AOD. In a previous study, the AOD was found to increase with latitude between equator and $12^{\circ} \mathrm{N}$, while over northern $\mathrm{AS}$, it did not show significant latitudinal variations (Satheesh et al., 2006a). These researchers reported mean AOD values of $0.29 \pm 0.12$ during the winter monsoon season (November to March) and $0.47 \pm 0.14$ during the summer monsoon season (April to September). The respective $\alpha$ values were 
$0.7 \pm 0.12$ and $0.3 \pm 0.08$. The differences in the AOD spatial distribution between the present study and that by Satheesh et al. (2006a) are mainly attributed to the differences in the season, location of the measurements, and the fact that the present study does not include data south of $8^{\circ} \mathrm{N}$, where the AOD has been observed to be lower without a strong continental influence (Satheesh et al., 2006a). In addition to the latitudinal variation, a longitudinal gradient is observed, with a large decrease in $\mathrm{AOD}_{500}$ values from the Indian coast towards the far AS. As the distance from the coast increases the continental anthropogenic aerosols undergo changes in size due to coagulation and condensation, and would also be removed from the atmosphere by sedimentation and precipitation processes. Kedia and Ramachandran (2008b) investigated the AOD variation with distance from the coast during ICARB. They found that the scaling distance (distance from the coast at which the AOD becomes 1/e of its value) was $\sim 2000 \mathrm{~km}$ in AS. Ramachandran (2004b) has indicated the importance of wind speed over oceanic regions in altering the aerosol spectral characteristics and the effect it has on the gradients seen in terms of the continental influence. Close to the Indian subcontinent aerosol-mass concentrations were found to range between 21 and $53 \mu \mathrm{g} \mathrm{m}^{-3}$ (Nair et al., 2004) and were significantly larger than those near the Maldives $\left(\sim 19 \mathrm{\mu g} \mathrm{m}^{-3}\right)$ and at the Kaashidhoo Climate Observatory $\left(4.9^{\circ} \mathrm{N}, 73.5^{\circ} \mathrm{E}\right)$, far away from the coast (Ramanathan et al., 2001).

The $\alpha_{340-1020}$ values are high (above 1.0) in the central part of the AS closely associated with the low $\mathrm{AOD}_{500}$ values (Fig. 8 bottom panel). It is worth noting that in the far AS (west of $60^{\circ} \mathrm{E}$ ) the $\alpha_{340-1020}$ values remained high, without showing strong influence from the arid regions of the Arabian Peninsula. In contrast, low $\alpha_{340-1020}$ values are observed in the north part of AS, thus indicating the influence of desert-dust particles transported over this region. The strong south-to-north gradient in $\alpha_{340-1020}$ values around $15-16^{\circ} \mathrm{N}$ is characteristic, with $\alpha_{340-1020}$ values above 0.9 in the south and below 0.8 in the north. However, the most common situation is the intermediate values of $\alpha_{340-1020}$ (near to 0.9 ), indicating a mixed aerosol field over AS from both anthropogenic and natural emissions. Mixed aerosols also dominate near to the Indian coast (Kalapureddy et al., 2009). Unlike the other marine regions, where sea-salt aerosols contribute mostly to the total aerosol-mass concentrations (Smirnov et al., 2002), the aerosol chemical composition analysis performed over IO and Kaashidhoo during INDOEX 1999 found that the sea salt contributes only $11 \%$ and $17 \%$ to the total AOD, respectively (Ramanathan et al., 2001; Satheesh et al., 2002). Furthermore, Satheesh et al. (2006b) found that the sea-salt contribution to the AOD was about $20-30 \%$ in the northern AS and $30-40 \%$ in the southern. This fact can partly explain the relative high $\alpha$ values over the far AS. It is well known that the northern AS is influenced by the Indian subcontinent and West Asian arid regions, whereas the southern AS and northern IO are influ-

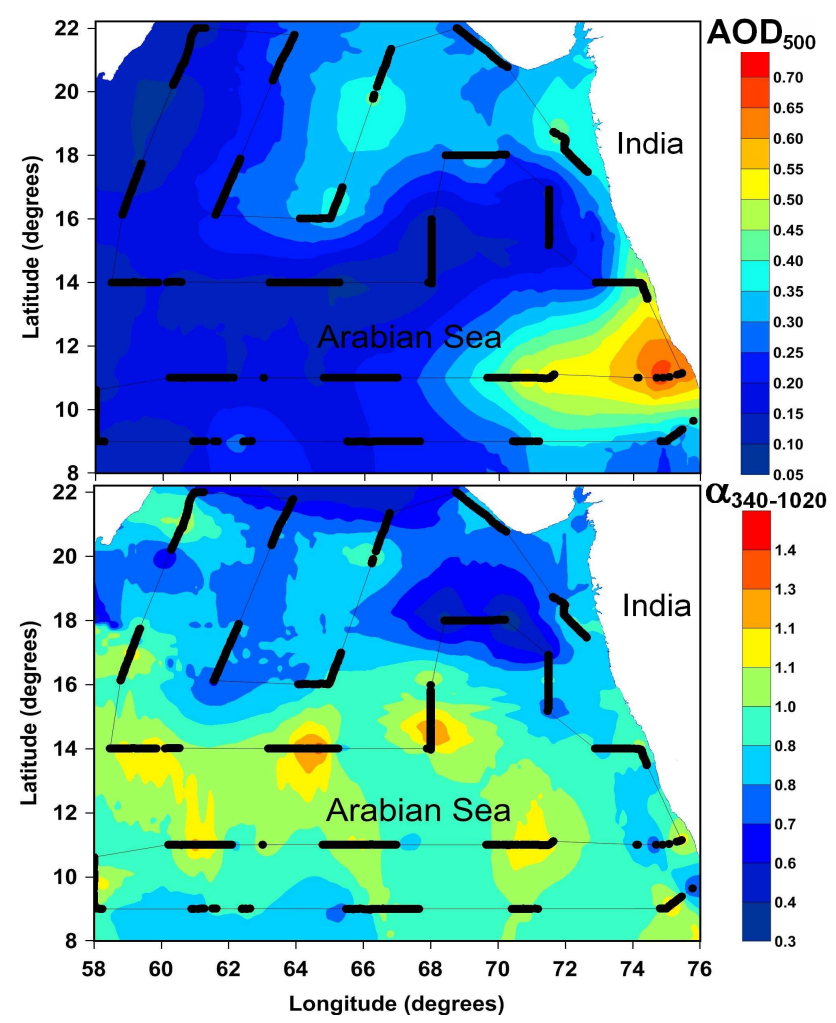

Fig. 8. Spatial distribution of the $\mathrm{AOD}_{500}$ (top) and $\alpha_{340-1020}$ (bottom) values regarding the whole set of measurements over the AS region. The ship track is shown in black line, while the positions of the sun photometric measurements are indicated with dots. Note that the sun photometric measurements were taken only in daytime and under cloudfree sky.

enced by several source regions where the ITCZ has a great impact (Nair et al., 2004; Satheesh et al., 2006a). Extensive measurements over AS from the Minicoy Island (Moorthy and Satheesh, 2000) have shown that the AOD is higher during the summer monsoon, whereas its spectral variation is significant during winter, showing an important seasonal variation. Therefore, the influence of the local monsoon system on the seasonal aerosol properties over AS is very important and must be examined in further detail.

In Fig. 9 (left and right panels) the spatial distribution of the $a_{1}$ values over AS is shown for the spectral bands of 340$1020 \mathrm{~nm}$ and $340-870 \mathrm{~nm}$, respectively. In general, the two maps agree with each other. More specifically, large negative $a_{1}$ values are depicted in the far and central AS, while over north AS and along the Indian coast $a_{1}$ is smaller in absolute value. In general for the south AS, $a_{1}$ for $340-1020 \mathrm{~nm}$ is smaller in absolute value than $a_{1}$ for $340-870 \mathrm{~nm}$. However, this area is associated with very low AODs and the estimated errors may be high. Thus, the inclusion of the $\mathrm{AOD}_{1020}$ value in the polynomial fit may produce large differences in the $a_{1}$ values. The correlation of the $a_{1}$ values in the two spectral bands exhibits large scatter $\left(R^{2}=0.30\right)$, further highlighting 


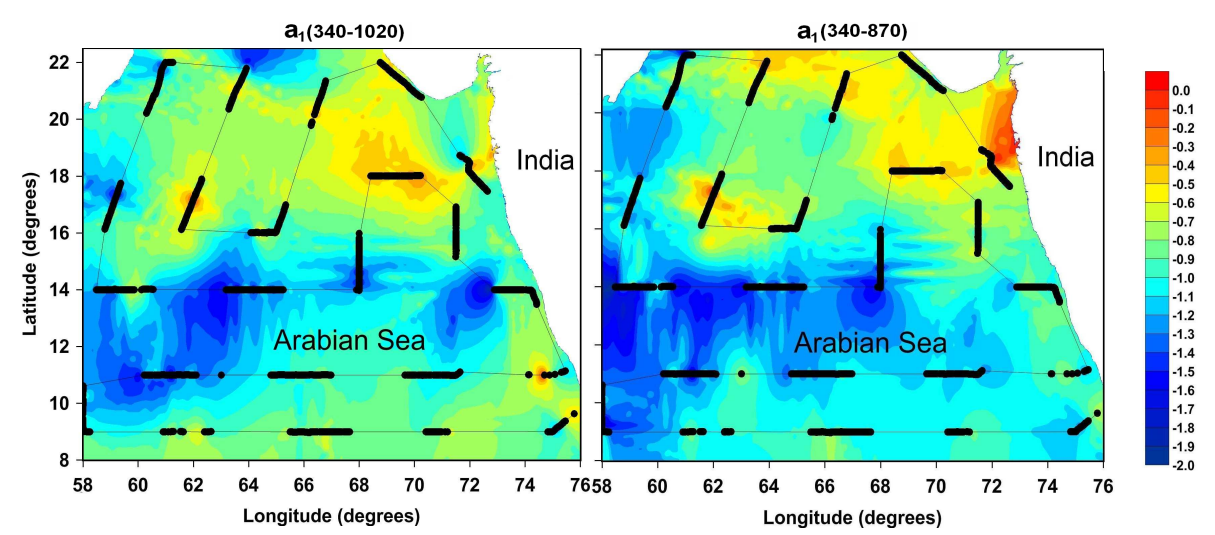

Fig. 9. Same as Figure 8 but for $a_{1}$ values regarding the whole set of measurements over the AS region computed in the 340-1020-nm band (left) and the 340-870-nm band (right).

the great importance of the wavelength interval used for such computations.

The most important parameter of the polynomial fit is the $a_{2}$ value, which presents the curvature of the AOD spectral distribution in logarithmic coordinates and can be used as an additional tool for the aerosol-type discrimination (Kaskaoutis et al., 2007a). The spatial distribution of both $a_{2}$ values is shown in Fig. 10 (left and right panels) for the 340-1020 and 340-870 nm, respectively. Positive values of $a_{2}$ are indicative of convex-type curves closely associated with coarse-mode particles, while negative curvatures with fine-mode aerosols. Near to zero $a_{2}$ values are indicative of bimodal aerosol size distributions with similar contributions of coarse and fine particles. The majority of the area is covered with negative $a_{2}$ values for both wavelength ranges over most of the southern and central parts of AS, indicating aerosols having a large fine-mode fraction. On certain occasions, positive $a_{2}$ values were also found in the southern part of AS, especially in left panel of Fig. 10. Furthermore, the inclusion of $\mathrm{AOD}_{1020}$ in the $a_{2}$ retrievals results in larger fraction of positive $a_{2}$ values $(\sim 49 \%)$ against $\sim 35 \%$ for the $340-870 \mathrm{~nm}$ case, a scenario that seems to be more likely over an oceanic environment. Points with concurrent positive $a_{2}$ values from the $340-1020 \mathrm{~nm}$ band with negative $a_{2}$ from the $340-870 \mathrm{~nm}$ were mainly observed near the Indian coast and in the south AS. Therefore, the spectral band used for the $a_{2}$ retrievals affect the resulting $a_{2}$, as the coefficient of determination between the two sets of $a_{2}$ values is low, $R^{2}=0.23$. Positive values of the $a_{2}$ (in both Figures) are observed in the northern AS, where the high AODs are dominated by coarse-mode aerosols. Over these regions the $a_{1}$ values are less negative (Fig. 9) while the $\alpha_{340-1020}$ values the lowest (Fig. 8 bottom panel).

\subsection{Classification of aerosol properties over AS sub-regions}

Aerosol spectral measurements can be characterized by 3 independent variables: i) the AOD, ii) the Ångström exponent $(\alpha)$, and iii) the spectral curvature of $\alpha\left(a_{2}\right.$ or $\left.d \alpha\right)$. Gobbi et al. (2007) proposed a simple graphical method to visually convert $(\alpha, d \alpha)$ to the contribution of fine aerosol to the AOD and the size of the fine particles. This classification scheme is based on Mie calculations and correlates the $\alpha$ vs. $d \alpha$ plot with the fine-mode fraction at $675 \mathrm{~nm}$ and effective radius of fine aerosols. The same scheme was performed over AS and three sub-regions for a first time over an oceanic environment. However, there are three differences in applying the classification scheme to the oceanic data as opposed to its previous uses: 1) the classification scheme was performed via Mie calculations using a complex refractive index, $m$, of 1.4-0.001 $i$, which is typical for urban/industrial aerosols and may not accurately represent $\mathrm{m}$ of the aerosols over the AS; 2) the classification scheme is applied over much larger regional scales instead of a more localized AERONET site as in the past (Gobbi et al., 2007; Basart et al., 2009); and 3) the data for $\alpha$ and $d \alpha$ over the oceanic regions contain much higher variability than found at the continental AERONET sites. For example Gobbi et al. (2007) used only cases with AOD>0.15 from AERONET to avoid errors larger than $\sim 30 \%$. In the present analysis the whole set of observations was used in order to reveal any systematic uncertainties over oceanic regions.

The classified three sub-regions of AS and entire AS regions have been used in Fig. 11a-d. Due to the bimodal aerosol-size distribution, very different values of $\alpha$ were observed in different wavelength intervals due to the significant wavelength dependence of the Ångström exponent. The Ångström exponent difference $(d \alpha)$ was defined as $d \alpha=$ $\alpha(440-675)-\alpha(675-870)$. It should be mentioned here that the differences occurred between the $\alpha, d \alpha$ values with those 

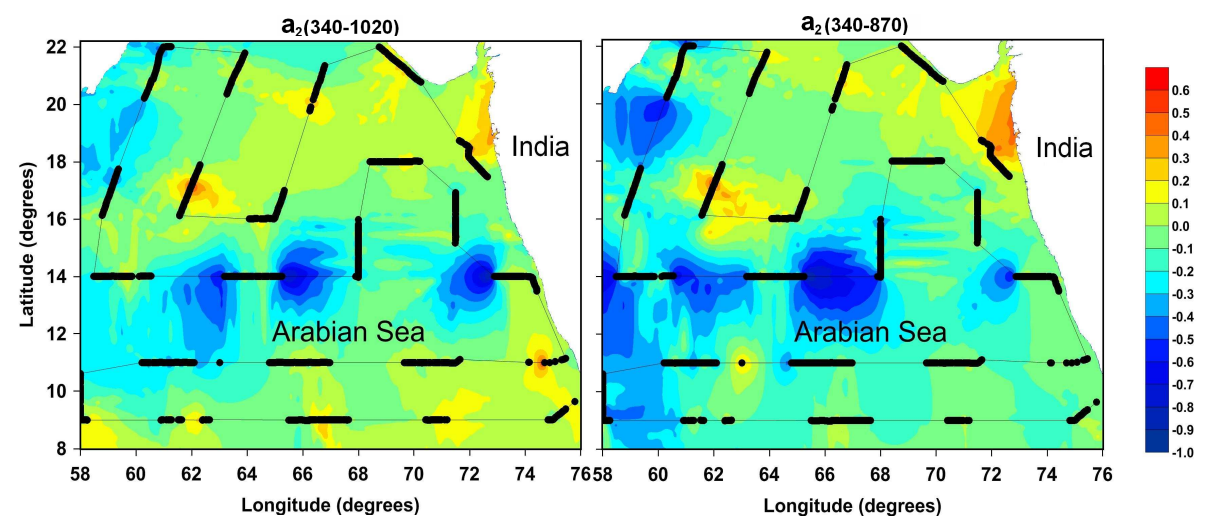

Fig. 10. Same as Fig. 9, but for the $a_{2}$ values.

of $\alpha, a_{2}$ presented before are attributed to the different wavelength bands used in the computations. Note also that the consistency between the $d \alpha$ and the curvature $\left(a_{2}\right)$ presupposes the same wavelength range (Kaskaoutis et al., 2007a). In Fig. 11a-d the aerosols are classified by representing their $\mathrm{AOD}_{500}$ by different colors.

Over the entire AS, a large fraction of data points are out of the classification scheme, mainly exhibiting large (positive) $d \alpha$ differences. This occurs because of larger uncertainties in the computations leading to a large spectral variation of $\alpha$ (note that the majority of these points correspond to $\mathrm{AOD}<0.2)$ and because the scheme was constructed for refractive index of urban/industrial aerosols. Negative differences indicate the dominance of fine-mode aerosols, while near to zero or positive indicate the effect of two separate (fine and coarse) modes.

In the coastal AS, nearly all the points are within the classification scheme. Increasing AOD shows a shift to larger $\alpha$ values (0.8-1.1) with effective radius between 0.10 and $0.15 \mu \mathrm{m}$. The positive $d \alpha$ indicates that these aerosols are of bimodal distribution having a large coarse-mode fraction (between 0.3 and 0.5). In contrast to the coastal AS, the high AODs in the mid AS are associated with $\alpha<0.8$, while for $\mathrm{AOD}<0.3$ a wide range of $d \alpha$ is observed. Pure dust conditions associated with $\alpha \sim 0.4, n<30 \%$ and $d \alpha$ (from -0.1 to 0.3 ) are also observed (29 April). The mid AS was found to be the most inhomogeneous region with significant contributions of various aerosol types (Kalapureddy et al., 2009). These heterogeneities are clearly depicted in the $\alpha$ vs. $d \alpha$ plot.

The AOD classification in far AS is different from the other regions, since all the $\mathrm{AOD}_{500}$ values are below 0.3. The spectral aerosol characteristics can be, in general, divided into two groups for a threshold of $\mathrm{AOD}_{500} \sim 0.2$. Cases with lower AODs exhibit larger $\alpha$ values, also having a wide range of $\mathrm{n}$ and $d \alpha$. For $\mathrm{AOD}_{500}>0.2$ the $\alpha$ shifts towards lower values, while the aerosol field may composed of fine $(n>0.6)$ or coarse $(n<0.3)$ particles. However, the coarse particles dominate, especially for $\mathrm{AOD}_{500}>0.25(d \alpha>0.1$ and $n \sim 0.2)$.
Despite the fact that the classification scheme is based on theoretical calculations and the uncertainties in sunphotometric measurements over oceanic regions, and especially over a moving platform, may be large. Figure 11 highlights the large heterogeneities in spectral aerosol properties over the AS sub-regions. The $\alpha$ vs. $d \alpha$ plots present large differences compared to those obtained over continental AERONET sites (Gobbi et al., 2007; Basart et al., 2009) and it is difficult to see any evidence of hygroscopic and/or coagulation growth from aging of the fine aerosols. However, because this is the first time that this scheme has been applied over AS the data can serve as a basis for comparative studies conducted in other seasons or in the BoB.

\section{Comparison between MABL and columnar aerosol characteristics}

Nair et al. (2008) have investigated the spatial distribution of the sea-surface mass concentration and the fine-mode mass fraction over AS during ICARB. They found a generally low mass concentration of $16.7 \pm 7 \mu \mathrm{g} \mathrm{m}^{-3}$, almost half of that reported in previous campaigns (e.g., INDOEX). The coarsemode aerosols (radii $>1.0 \mu \mathrm{m}$ ) contributed, on average, 58\% to the total aerosol mass in the MABL; note that the air-mass trajectories at $500 \mathrm{~m}$ (not shown) is of marine origin that justifies the larger presence of coarse-particles. For $62 \%$ of the measurements, the fine-mode fraction was between 0.35 and 0.55 , while in $4 \%$ of the data this fraction was $>0.75$, with the higher fraction of fine-mode particles found mainly over the regions with negative $a_{2}$ values. More specifically, in the central AS, bounded by $65-70^{\circ} \mathrm{E}$ and $10-15^{\circ} \mathrm{N}$, Nair et al. (2008) found that, although the aerosol-mass concentration was low $\left(<15 \mu \mathrm{g} \mathrm{m}^{-3}\right)$, the contribution of accumulation aerosols to the total mass was greater than $50 \%$. They had attributed it to faster dry deposition of aerosols, particularly of the coarse mode, caused by the strong descent of air masses associated with the strong low-level anticyclone flow prevailing over the area. The MABL aerosol characteristics (Nair et 


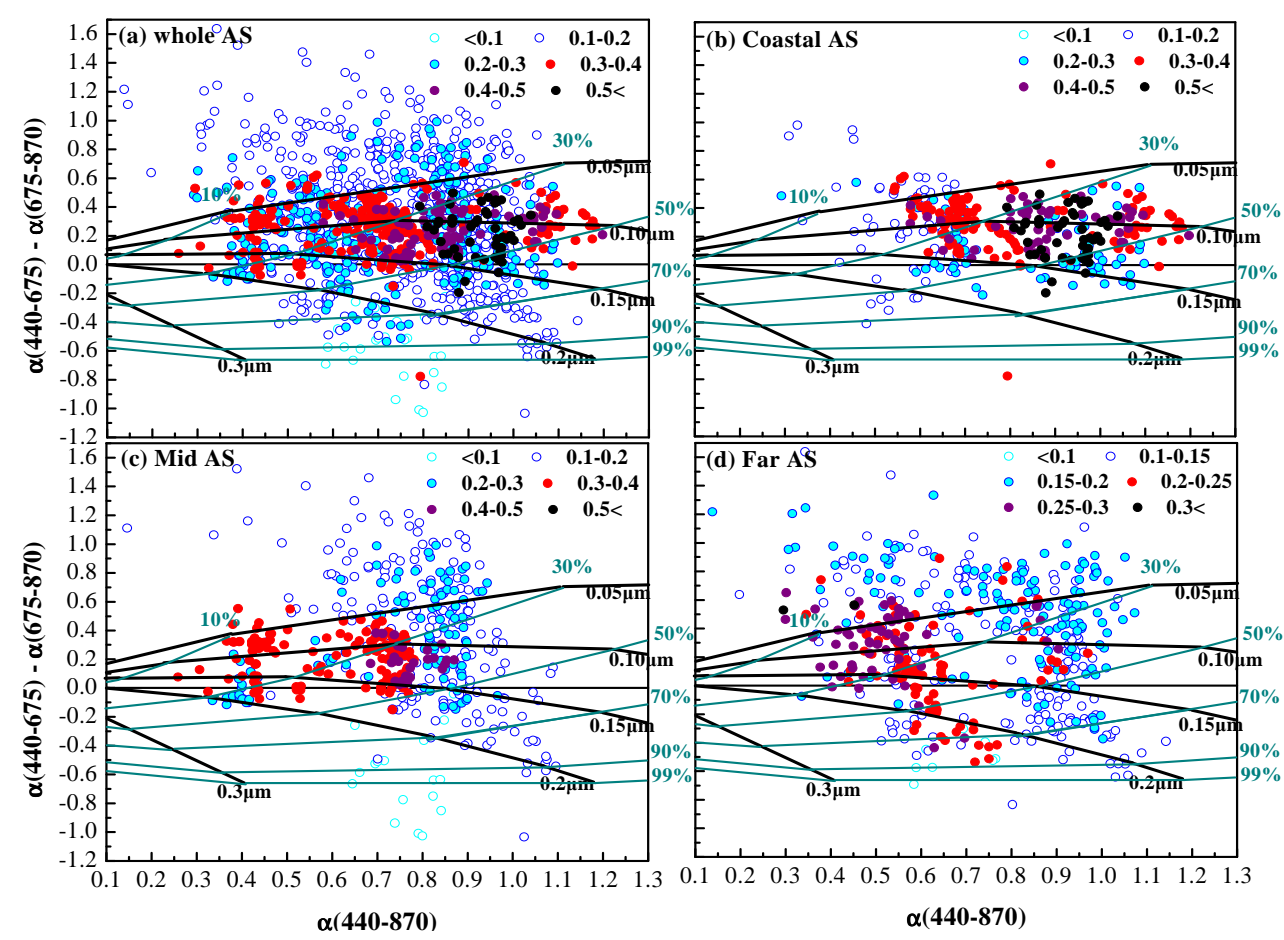

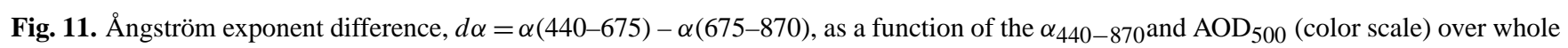
AS (a), coastal AS (b), mid AS (c), and far AS (d).

al., 2008) are in general agreement with the columnar ones (our study), since in the same area $\mathrm{AOD}_{500}$ is low (Fig. 8 top panel), $\alpha$ high (Fig. 8 bottom panel) and $a_{2}$ negative (Fig. 10). Nair et al. (2008) also found high values of mass concentration $\left(\sim 30 \mu \mathrm{g} \mathrm{m}^{-3}\right)$ in the northern AS $\left(64-68^{\circ} \mathrm{E}\right.$, $19-22^{\circ} \mathrm{N}$ ), which are mainly attributed to aerosol transport from arid regions of West Asia, since the effective radius was from about 0.3 to 0.4 and the fine-mode fraction below 0.5. The presence of large $\mathrm{AOD}_{550}$ associated with desert particles $\left(\alpha<0.75, a_{2}>0\right)$ was also revealed by our analysis over this area. Finally, relative high aerosol-mass concentrations $\left(20 \pm 7 \mu \mathrm{g} \mathrm{m}^{-3}\right)$ were measured along the West Indian coast, mainly composed of anthropogenic emissions (Nair et al., 2008). The present results also show increased $\mathrm{AOD}_{500}$ values over this region associated with urban/industrial pollution transport over AS. A direct correlation between the MABL aerosol characteristics (Nair et al., 2008) and columnar ones (present study) will reveal heterogeneities in the aerosol field in the vertical and constitute a real challenge. However, the different air-mass origin between the lower and upper atmospheric levels (not shown) may be the main reason for any differences observed between MABL and columnar aerosol characteristics.

Aerosols found over the oceans are mainly sea-salt particles, produced by the evaporating water droplets injected into the atmosphere, and wind-blown dust, transported from the surrounding landmasses. Over the pristine oceanic regions the major contribution to the AOD is from sea salt and sulfate from natural sources. The emission strength of these aerosols is dependent strongly on the surface wind speed. Over the northern IO it has been seen that sea salt and sulfate from natural sources contribute less than 20\% to the AODs (Ramanathan et al., 2001; Satheesh et al., 2002), while BC, fly ash, dust, organics and anthropogenic sulfate contribute the remaining $80 \%$ to the AOD. As mineral dust particles can be transported over long distances, they can contribute significantly to the aerosol mass in the marine atmosphere (Quinn et al., 2002). Even though it is possible that the oceanic environment is less heterogeneous compared to the land one, several studies have shown that the aerosol properties show significant variations, even over reasonably small spatial and temporal scales (e.g., Moorthy and Satheesh, 2000; Smirnov et al., 2002). The present results highlight the large heterogeneities in the columnar aerosol characteristics over AS, which are in general agreement with measurements in the MABL.

\section{Conclusions}

Ship-borne sunphotometric measurements of spectral AOD were performed over AS during the pre-monsoon season (April-May 2006) in order to shed light on the spatiotemporal aerosol heterogeneity. The present study provides an extensive analysis regarding the errors and the uncertainties in computing the aerosol optical properties. It was found 
that the use of the spectral band of 340-1020 nm for the polynomial fit of $\ln \tau_{\lambda}$ vs. $\ln \lambda$ gave more accurate results than the respective of 340-870 nm. The spectral AOD and $\alpha$ values exhibited significant day-to-day variations along the ship cruise mainly depending on the distance from the main land masses, the air-mass origin and atmospheric dynamics. The mean $\mathrm{AOD}_{500}$ was found to be $0.25 \pm 0.11$ and the $\alpha_{340-1020}$ $0.90 \pm 0.19$. In the majority of the cases the coefficient $a_{2}$ was negative, thus implying a concave-type curve indicative of the higher presence of fine-mode aerosols. The data presented a strong latitudinal and longitudinal gradient in the AOD and Ångström exponent. The AODs were found to exhibit a steep gradient as the ship moved from the Indian coast towards the pristine oceanic region, with higher values near the coast and northern part of AS and very low values in the central part of AS. The Ångström exponent also exhibited significant spatial variation, with the higher values to be detected near the Indian coast and in the far AS. The anthropogenic and urban activities along the densely populated western coast of India could be attributed to the former; the later arose from the strong vertical descent of rather clean air, associated with low-level mid-ocean anticyclone, which lead to faster depletion of coarse-mode particle concentration. Low values of $\alpha$ associated with coarse-mode arid aerosols were found in north AS. The present study was the very first one providing the spatial distribution of the coefficients $a_{1}$ and $a_{2}$ over AS even in two spectral bands. A general agreement was found in the spatial distribution of each coefficient determined in different wavelength bands, despite some differences observed in the south AS. Positive values of $a_{2}$ (indicative of coarse-mode aerosols) were mainly observed in the northern AS. Negative $a_{2}$ values (finemode aerosol abundance) were observed in the central and far AS. In addition to the transport of dust from the arid West Asian regions, convex curvature could also arise from the presence of sea-salt particles as the measurements were conducted over oceanic regions and from well-mixed aerosols with significant contribution of coarse-mode. The comparison between MABL and columnar aerosol characteristics revealed a general agreement in their spatial distribution over AS.

The results indicated a relatively complicated aerosol mixture of both industrial pollution and mineral dust. This warrants the need for careful measurements and analysis to discriminate the dominance of specific aerosol types (e.g., anthropogenic aerosols, maritime particles, mineral dust) in the AS. The combination of such particle types is highly variable and makes attribution of the aerosol radiative properties to specific aerosol types difficult to be detected without detailed and precise measurements.

Acknowledgements. The present study was supported and funded by the Geosphere Biosphere program of the Indian Space Research Organization. The authors are grateful to the Reviewers for their valuable comments. We are grateful to William E. Asher, the handling editor for the valuable comments and corrections to the manuscript. Thanks are also due the Director, IITM for constant encouragement.

Edited by: W. E. Asher

\section{References}

Ångström, A. K.: Techniques of determining the Turbidity of the Atmosphere, Tellus, XIII, 214-223, 1961.

Babu, S. S., Moorthy, K. K., and Satheesh, S. K.: Aerosol black carbon over Arabian sea during inter monsoon and summer monsoon seasons, Geophys. Res. Lett., 31, L06104, doi:10.1029/2003GL018716, 2004.

Babu, S. S., Nair, V. S., and Moorthy, K. K.: Seasonal changes in aerosol characteristics over Arabian Sea and their consequence on aerosol short-wave radiative forcing: Results from ARMEX field campaign, J. Atmos. Solar Terr. Phys., 70, 820-834, 2008.

Basart, S., Pérez, C., Cuevas, E., Baldasano, J. M., and Gobbi, G. P.: Aerosol characterization in Northern Africa, Northeastern Atlantic, Mediterranean Basin and Middle East from direct-sun AERONET observations, Atmos. Chem. Phys., 9, 8265-8282, doi:10.5194/acp-9-8265-2009, 2009.

Beegum, N. S., Moorthy, K. K., Nair, V. S., et al.: Characteristics of Spectral Aerosol Optical Depths over India during ICARB, J. Earth System Sci., 117(S1), 303-313, 2008.

Cachorro, V. E., Romero, P. M., Toledano, C., Cuevas, E., and de Frutos, A. M.: The fictitious diurnal cycle of aerosol optical depth: A new approach for "in situ" calibration and correction of AOD data series, Geophys. Res. Lett., 31, L12106, doi:10.1029/2004GL019651, 2004.

Eck, T. F., Holben, B. N., Reid, J. S., Dubovik, O., Smirnov, A., O'Neill, N. T., Slutsker, I., and Kinne, S.: Wavelength dependence of the optical depth of biomass burning, urban, and desert dust aerosols, J. Geophys. Res., 104(D24), 31333-31349, 1999.

Eck, T. F., Holben, B. N., Dubovik, O., Smirnov, A., Slutsker, I., Lobert, J. M., and Ramanathan, V.: Column-integrated aerosol optical properties over the Maldives during the northeast monsoon for 1998-2000, J. Geophys. Res., 106, 28555-28566, 2001.

El-Metwally, M., Alfaro, S. C., Abdel Wahab, M., and Chatenet, B.: Aerosol characteristics over urban Cairo: Seasonal variations as retrieved from Sun photometer, J. Geophys. Res., 113, D14219, doi:10.1029/2008JD009834, 2008.

Fitzgerald, J. W.: Marine aerosols: A review. Atmos. Environ., 25A, 533-545, 1991.

George, S. K. and Nair, P. R.: Aerosol mass loading over the marine environment of Arabian Sea during ICARB: Sea-salt and nonsea-salt components, J. Earth System Sci., 117, 333-344, 2008.

Giver, L. P., Chackerian Jr. C., and Varanasi, P.: Visible nearinfrared H20 line intensity corrections for HITRAN96J, J. Quant. Spectrosc. Ra., 66, 101-105, 2000.

Gobbi, G. P., Kaufman, Y. J., Koren, I., and Eck, T. F.: Classification of aerosol properties derived from AERONET direct sun data, Atmos. Chem. Phys., 7, 453-458, doi:10.5194/acp-7-453-2007, 2007.

Gueymard C.: SMARTS2, a simple model of the atmospheric radiative transfer of sunshine - algorithms and performance assessment, FSEC-PF-270-93, Florida Solar Energy Center, Cocoa, FL, 1995. 
Haywood, J. M., Ramaswamy, V., and Soden, B. J.: Tropospheric aerosol climate forcing in clear-sky satellite observations over the oceans, Science, 283, 1299-1303, 1999.

Hess, A. M., Koepke, P., and Schult, I.: Optical properties of aerosol and clouds: the software package OPAC, B. Am. Meteorol. Soc., 79, 831-844, 1998.

Holben, B. N., Eck, T. F., Slutsker, J., et al.: AERONET-A federated instrument network and data archive for aerosol characterization, Remote Sens. Environ., 66, 1-16, 1998.

Junge, C. E.: The size distribution and aging of natural aerosols as determined from electrical and optical measurements in the atmosphere, J. Meteorol., 12, 13-25, 1955.

Kalapureddy, M. C. R. and Devara, P. C. S.: Characterization of aerosols over oceanic regions around India during pre-monsoon 2006, Atmos. Environ., 42, 6816-6827, doi:10.1016/j.atmosenv.2008.05.022, 2008.

Kalapureddy, M. C. R., Ernest Raj, P., and Devara, P. C. S.: Total column ozone variations over oceanic region around Indian sub-continent during pre-monsoon of 2006, Atmos. Chem. Phys. Discuss., 8, 3143-3162, doi:10.5194/acpd-8-3143-2008, 2008.

Kalapureddy, M. C. R., Kaskaoutis, D. G., Ernest Raj, P., Devara, P. C. S., Kambezidis, H. D., Kosmopoulos, P. G., and Nastos, P. T.: Identification of aerosol type over the Arabian Sea in the premonsoon season during the ICARB campaign, J. Geophys. Res., 114, D17203, doi:10.1029/2009JD011826, 2009.

Kaskaoutis, D. G. and Kambezidis, H. D.: Investigation on the wavelength dependence of the aerosol optical depth in the Athens area, Q. J. Roy. Meteorol. Soc., 132, 2217-2234, 2006.

Kaskaoutis, D. G., Kambezidis, H. D., Adamopoulos, A. D., and Kassomenos, P. A.: Comparison between experimental data and modeling estimates of atmospheric optical depth over Athens, Greece, J. Atmos. Solar Terr. Phys., 68, 1167-1178, 2006.

Kaskaoutis, D. G., Kambezidis, H. D., Hatzianastassiou, N., Kosmopoulos, P. G., and Badarinath, K. V. S.: Aerosol climatology: dependence of the Angstrom exponent on wavelength over four AERONET sites, Atmos. Chem. Phys. Discuss., 7, 7347-7397, doi:10.5194/acpd-7-7347-2007, 2007.

Kaskaoutis, D. G., Kambezidis, H. D., Kharol, S. K., and Badarinath, K. V. S.: Investigation on the ozone and trace gases contribution to the total optical depth in a polluted urban environment, Atmos. Res., 86, 286-296, 2007b.

Kaskaoutis, D. G. and Kambezidis, H. D.: Comparison of the Ångström parameters retrieval in different spectral ranges with the use of different techniques, Meteorol. Atmos. Phys., 99, 233246, 2008

Kedia, S. and Ramachandran, S.: Latitudinal and longitudinal variation in aerosol characteristics from Sun photometer and MODIS over the Bay of Bengal and Arabian Sea during ICARB, J. Earth System Sci., 117, 375-387, 2008a.

Kedia, S. and Ramachandran, S.: Features of aerosol optical depths over the Bay of Bengal and the Arabian Sea during premonsoon season: Variabilities and anthropogenic influence, J. Geophys. Res., 113, D11201, doi:10.1029/2007/JD009070, 2008b.

King, M. D. and Byrne, D. M.: A method for inferring total ozone content from spectral variation of total optical depth obtained with a solar radiometer, J. Atmos. Sci., 33, 2242-2251, 1976.

Krishnamurti, T. N., Jha, B., Prospero, J., Jayaraman, A., and Ramanathan, V.: Aerosol and pollutant transport and their impact on radiative forcing over the tropical Indian Ocean during the
January-February 1996 pre-INDOEX cruise, Tellus, 50B, 521542, 1998.

Kumar, A., Sarin, M. M., and Sudheer, A. K.: Mineral and anthropogenic aerosols in Arabian Sea-atmosphere boundary layer: Sources and spatial variability, Atmos. Environ., 42, 5169-5181, doi:10.1016/j.atmosenv.2008.03.004, 2008.

Li, F. and Ramanathan, V.: Winter to summer monsoon variation of aerosol optical depth over the tropical Indian Ocean, J. Geophys. Res., 107(D16), 4284, doi:10.1029/2001JD000949, 2002.

Madhavan, B. L., Niranjan, K., Sreekanth, V., Sarin, M. M., and Sudheer, A. K.: Aerosol characterization during the summer monsoon period over a tropical coastal Indian station, Visakhapatnam, J. Geophys. Res., 113, D21208, doi:10.1029/2008JD010272, 2008.

Moorthy, K. K., Niranjan, K., Narasimhamurthy, B., et al.: Aerosol climatology over India: 1. ISRO GBR MWR network and database, ISRO GBR SR-03-99, Indian Space Res. Organ., Bangalore, 1999.

Moorthy, K. K. and Satheesh, S. K.: Characteristics of aerosols over a remote island, Minicoy in the Arabian Sea: optical properties and retrieved size characteristics, Q. J. Roy. Meteorol. Soc., 126, 81-109, 2000.

Moortrhy, K. K., Saha, A., Prased, B. S. N., Niranjan, K., Jhurry, D., and Pillai, P. S.: Aerosol optical depths over peninsular India and adjoining oceans during the INDOEX campaigns: spatial, temporal and spectral characteristics, J. Geophys. Res., 106(D22), 28539-28554, 2001.

Moorthy, K. K., Babu, S. S., and Satheesh, S. K.: Aerosol characteristics and Radiative Impacts over the Arabian Sea during the Intermonsoon Season: Results from the ARMEX field campaign, J. Atmos. Sci., 62, 192-206, 2005.

Moorthy, K. K., Satheesh, S. K., Babu, S. S., and Dutt, C. B. S.: Integrated Campaign for Aerosols, gases and Radiation Budget (ICARB): An overview, J. Earth System Sci., 117(S1), 243-262, 2008.

Moorthy, K. K., Nair, V. S., Babu, S. S., and Satheesh, S. K.: Spatial and vertical heterogeneities in aerosol properties over oceanic regions around India: Implications for radiative forcing, Q. J. Roy. Meteorol. Soc., 135, 2131-2145, doi:10.1002/qj.525, 2009.

Morys, M., Mims III, F. M., Hagerup, S., Anderson, S. E., Baker, A., Kia, J., and Walkup, T.: Design, calibration, and performance of MICROTOPS II handheld ozone monitor and sun photometer, J. Geophys. Res., 106, 14573-14582, 2001.

Nair, P. R., Parameswaran, K., Sunil Kumar, S. V., and Rajan, R.: Continental influence on the spatial distribution of particulate loading over the Indian Ocean during winter season, J. Atmos. Solar Terr. Phys., 66, 27-38, 2004.

Nair, V. S., Moorthy, K. K., and Babu, S. S.: Size segregated aerosol mass concentration measurements over the Arabian Sea during ICARB, J. Earth System Sci., 117, 315-323, 2008.

O’Neill, N. T., Dubovic, O., and Eck, T. F.: Modified Ångström exponent for the characterization of submicrometer aerosols, Appl. Optics, 40(15), 2368-2375, 2001.

Quinn, P. K., Coffman, D. J., Bates, T. S., Miller, T. L., Johnson, J. E., Welton, E. J., Neusüss, C., Miller, M., and Sheridan, P .J.: Aerosol optical properties during INDOEX 1999:Means, variability, and controlling factors, J. Geophys. Res., 107(D19), 8020, doi:10.1029/2000JD000037, 2002.

Ramachandran, S. and Jayaraman, A.: Premonsoon aerosol 
loading and size distribution over the Arabian Sea and the Tropical Indian Ocean, J. Geophys. Res., 107, 4738, doi:10.1029/2002JD002386, 2002.

Ramachandran, S.: Spectral aerosol optical characteristics during the northeast monsoon over the Arabian Sea and the tropical Indian Ocean: 1. Aerosol optical depths and their variabilities, J. Geophys. Res., 109, D19207, doi:10.1029/2003JD004476, 2004a.

Ramachandran, S.: Spectral aerosol optical characteristics during the northeast monsoon over the Arabian Sea and the tropical Indian Ocean: 2. Angstrom and anthropogenic influence, J. Geophys. Res., 109, D19208, doi:10.1029/2003JD004483, 2004b.

Ramanathan, V., Crutzen, P. J., Lelieveld, J., Mitra, A. P., et al.: Indian Ocean Experiment: An integrated analysis of the climate and the great Indo-Asian haze, J. Geophys. Res., 106(D22), 28371-28398, 2001.

Reddy, L. A. K., Kulshrestha, U. C., Satyanarayana, J., Kulshrestha, M. J., and Moorthy, K. K.: Chemical characteristics of $\mathrm{PM}_{10}$ aerosols and air mass trajectories over Bay of Bengal and Arabian Sea during ICARB, J. Earth System Sci., 117, 345-352, 2008.

Reid, J. S., Eck, T. F., Christopher, S. A., Hobbs, P. V., and Holben, B. N.: Use of the Angstrom exponent to estimate the variability of optical and physical properties of aging smoke particles in Brazil, J. Geophys. Res., 104(D22), 27473-27489, 1999.

Satheesh, S. K., Ramanathan, V., Jones, L. X., Lobert, J. M., Podrogny, I. A., Prospero, J. M., Holben, B. N., and Loeb, N. G.: A model for the natural and anthropogenic aerosols for the tropical Indian Ocean derived from Indian Ocean experiment data, J. Geophys. Res., 104(D22), 27421-27440, 1999.
Satheesh, S. K., Ramanathan, V., Holben, B. N., Moorthy, K. K., Loeb, N. G., Maring, H., Prospero, J. M., and Savoie, D.: Chemical, microphysical, and radiative effects of Indian Ocean aerosols, J. Geophys. Res., 107(D23), 4725, doi:10.1029/2002JD002463, 2002.

Satheesh, S. K., Moorthy, K. K., Kaufman, Y. J., and Takemura, T.: Aerosol optical depth, physical properties and radiative forcing over the Arabian Sea, Meteorol. Atmos. Phys., 91, 45-62, 2006 a.

Satheesh, S. K., Srinivasan, J., and Moorthy, K. K.: Contribution of sea-salt to aerosol optical depth over the Arabian Sea derived from MODIS observations, Geophys. Res. Lett., 33, L03809, doi:10.1029/2005GL024856, 2006b.

Savoie, D. L., Prospero, J. M., and Nees, R. T.: Nitrate, non-sea-salt sulfate, and mineral aerosol over the northwestern Indian Ocean, J. Geophys. Res., 92(D1), 933-942, 1987.

Schuster, G. L., Dubovik, O., and Holben, B. N.: Angstrom exponent and bimodal aerosol size distributions, J. Geophys. Res., 111, D07207, doi:101029/2005JD006328, 2006.

Shaw, G. E.: Absorption continuum in the near IR near $1 \mu \mathrm{m}$, Appl. Optics, 19, 480-482, 1980.

Smirnov, A., Holben, B. N., Kaufman, Y. J., Dubovic, O., Eck, T. F., Slutsker, I., Pietras, C., and Halthore, R. N.: Optical properties of atmospheric aerosol in Maritime Environments, J. Atmos. Sci., 59, 501-523, 2002.

Smirnov, A., Holben, B. N., Slutsker, I., et al.: Maritime aerosol network as a component of Aerosol Robotic Network, J. Geophys. Res., 114, D06204, doi:10.1029/2008JD011257, 2009.

Tomasi, C., Marani, S., and Vitale, V.: Multiwavelength Sunphotometer Calibration corrected on the basis of the spectral features characterising particulate extinction and nitrogen dioxide absorption. Appl. Optics, 24, 2962-2970, 1985. 